\title{
Contra Teopompo: Formación retórica y escritura de la historia en Polibio
}

\section{Diego Alexander Olivera}

Instituto de Humanidades y Ciencias Sociales del Litoral, Consejo Nacional de Investigaciones Científicas y Técnicas / Universidad Nacional del Litoral, Argentina.

diego_alexander_olivera@yahoo.com.ar

Recibido: 10/03/20. Aceptado: 1/10/20.

\begin{abstract}
Resumen
El presente trabajo aborda la crítica que Polibio realiza contra Teopompo de Quíos desde una perspectiva que destaca su formación retórica. Se propone correr el foco de atención en lo que refiere a los motivos que llevan al de Megalópolis a lanzar una invectiva contra Teopompo enfatizando no en lo que se escribe, sino en cómo se escribe. El problema, entonces, es el modo en que el lógos resulta más efectivo para convencer respecto del conocimiento específico que el discurso historiográfico quiere trasmitir. La falta de coherencia o de claridad atribuida a Teopompo atenta contra la mencionada efectividad del discurso. De ahí que la discusión no se concentre en la veracidad de los hechos o su interpretación, sino en la habilidad para exponerlos con claridad, concisión y verosimilitud. Se afirma, a modo de conclusión, que en el centro de la diatriba se encuentra una retorización del discurso historiográfico que se debe, en parte, a que el uso de los ejercicios retóricos está asociado a determinadas virtudes del lógos.
\end{abstract}

Palabras Claves: historia, Polibio, retórica, Teopompo.

\section{Against Theopompus: Rhetorical Training and the Writing of History in Polybius}

\begin{abstract}
This article addresses the critique launched by Polybius against Theopompus of Chios from a perspective focused on his rhetorical training. It aims to move the focus of attention of the motives that drive the man from Megalopolis to cast an invective against Theopompus by emphasizing not what it is written, but how it is written. Thus, the matter under consideration is to what extent the lógos could be more effective to persuade in respect to a specific knowledge that historiographical discourse wishes to convey. The lack of coherence and clarity attributed to Theopompus undermines the
\end{abstract}


effectiveness of the discourse. That is why the debate does not ponder the truthfulness of events or their interpretation, but the ability to present them with clarity, conciseness and plausibility. As a conclusion, it is stated that in the heart of this diatribe exists a rhetorization of the historiographical discourse, in partly due to the awareness that the use of rhetorical exercises is linked to particular virtues of the lógos

Keywords: history, Polybius, rhetoric, Theopompus

\section{Introducción}

En el libro VIII de su Historia Polibio de Megalópolis realiza una dura crítica contra el también historiador Teopompo de Quíos a quien acusa de no escribir historia, sino un encomio, en referencia a las Filípicas. ${ }^{1}$ Más adelante, libro XXXVIII, vuelve a la carga con una diatriba contra el uso de digresiones que, si bien no menciona a Teopompo, en opinión de los especialistas modernos iba dirigida a él. ${ }^{2}$

Esas críticas han despertado el interés de los comentaristas modernos que enfatizaron en la teoría de la historia teopompea y sus diferencias con la de Polibio. Momigliano (1984), por ejemplo, veía en Teopompo un referente de la historiografía cínica, considerando, además, que la crítica polibiana oponía una historiografía de los hechos, la de Polibio, a una historiografía retórica, la del historiador de Quíos. Lens (1987) identificó, en la caracterización de Filipo hecha por Teopompo, el modelo odiseico, presente en la epopeya y en la comedia ática, y juzgó su obra como una historiografía psicológica. En esa línea, el acercamiento utilitario a la historia de parte de Polibio "le ha hecho incapaz de comprender un acercamiento psicológico" (Lens, 1987, p. 53).

Sin embargo, el megalopolitano apunta contra las formas de escribir la historia y no tanto contra la idea de historia. Bearzot (2005) señala que la invectiva de Polibio se concentra en las incongruencias y en las elecciones metodológicas y narrativas de Teopompo. Concluye que para el de Megalópolis la obra de Teopompo es incompatible con el êthos de un historiador, ya que su objetivo no es la verdad sino una utilidad personal de adular o engañar. En otras palabras, Polibio no discute tanto el juicio histórico de Teopompo como su honestidad intelectual. En cierto sentido la crítica tiene mucho de puesta en escena agonal, pues, como advierte Parmeggiani (2011, 2018), la cultura historiográfica de Polibio deriva principalmente de los historiadores del siglo IV. ${ }^{3}$ Por tanto, aunque estos aspectos de la polémica sacados a la luz por los estudios contemporáneos son relevantes, no terminan de dar cuenta del problema principal que enfatiza en la escritura de la historia.

Las investigaciones modernas han señalado también la importancia de la formación retórica, tanto en Teopompo como en Polibio, pero no ha sido suficiente como para insertar la crítica de Polibio dentro de un problema mucho mayor como es la relación entre historia y retórica. ${ }^{4}$ Aquí, por el contrario, se considera que es precisamente dicha formación retórica el núcleo de la crítica hecha por el megalopolitano. Un

\footnotetext{
1 Plb. VIII. 8-9.

2 Plb. XXXVIII. 6. 1-7. Cf. Walbank (1979, p. 692).

3 Bearzot (2005) también señala cierta admiración o imitación del método de Teopompo por parte de Polibio.

4 Sobre Teopompo, véase Momigliano (1984, p. 19), quien señala la adopción, por parte del historiador de Quíos, de técnicas provenientes de la escuela de Isócrates. Para Connor (1967, p. 151) el principal interés de Teopompo es la moralidad personal para lo cual su formación en oratoria epidíctica lo pone en condición de alabar o condenar. Sobre Polibio véase a Thornton (2013, pp. 21-42), quien defiende la idea del propio Polibio como un orador y analiza los aspectos formales de su obra como un verdadero discurso deliberativo. Además, considera que la articulación entre historiografía y oratoria en Polibio debe situarse en correspondencia con su actividad política en el contexto de las relaciones diplomáticas entre el mundo griego y Roma. Alexiou (2018) recupera la tesis de que Polibio está trabajando con los tratados de retórica del siglo IV a. C. o encomios reales, en especial, el Evágoras de Isócrates.
} 
abordaje desde la teoría progymnasmática permitirá dar cuenta de que esto es así, al observar cómo los ejercicios retóricos sirven a los historiadores como instancias de preparación antes de volcarse a la escritura de textos más complejos. Además, los especialistas modernos han obviado los testimonios provenientes de los antiguos manuales de retórica, lo que no es menor, ya que en uno de ellos, el de Teón escrito en el siglo I a. C., encontramos una crítica a Teopompo en sintonía con la de Polibio. En la perspectiva aquí tratada esa cita de Teón es significativa porque evidencia un hecho que se quiere resaltar; que detrás de la diatriba polibiana se encuentra una preocupación teórica sobre las formas correctas de utilizar los ejercicios retóricos en la escritura de una obra historiográfica.

Por tanto, el presente trabajo se divide en dos partes. La primera aborda el ejercicio retórico conocido como encomio y vituperio, que da lugar a la observación hecha por Polibio en el libro VIII sobre las incongruencias en el relato teopompeo. La segunda se concentra en la digresión como artilugio narrativo al que apelaban los historiadores antiguos y que, en el caso de Teopompo, su uso es cuestionado no solo por Polibio, sino también por el retor Teón. Finalmente, a modo de conclusión, se sostiene que la formación retórica de Polibio no es solo fundamental para comprender su obra; también lo es para comprender los juicios que emite sobre sus colegas.

\section{Sobre el encomio y el vituperio}

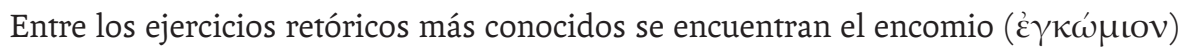
y el vituperio ( $\psi$ ó $0 \varsigma)$. Se trata de dos ejercicios muy útiles para escribir historia y biografías (Gibson, 2004; Alexiou, 2018). Sobre el primero se conservan los versos de Píndaro y, en prosa, el Encomio de Helena de Gorgias y Evágoras de Isócrates, mientras que las fuentes papiráceas, que datan del siglo II en adelante, lo tienen como el ejercicio mejor representado (Pordomingo, 2007). Polibio estaba familiarizado con ambos e incluso da cuenta de su práctica en las escuelas de retórica donde se componían elogios a Tersites o censuras a Penélope. ${ }^{5}$ De hecho, Polibio mismo compuso un encomio al estratego aqueo Filopemen, así como Teopompo compuso uno dedicado a Filipo II de Macedonia. ${ }^{6}$ Esto es relevante porque Polibio cuestiona el carácter marcadamente encomiástico de otras obras historiográficas al tratar el comportamiento de Filipo V en Mesene. ${ }^{7}$ Además, es en ese contexto donde se despacha contra Teopompo y su tratamiento de la figura del Rey macedonio:

Teopompo es quien, desde esta perspectiva, merece una reprensión más dura, porque

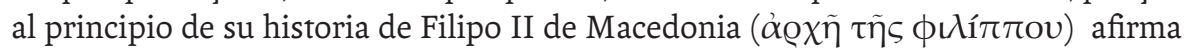

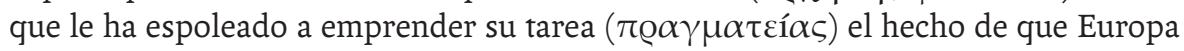
no ha producido nunca un hombre como Filipo hijo de Amintas, y al punto, después

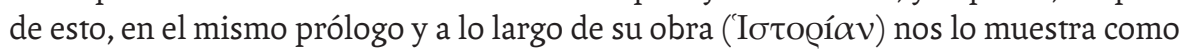
hombre extraordinariamente mujeriego ( $\gamma v v \alpha \ddot{i} \kappa \alpha \varsigma$ ), tanto, que sus vicios en este aspecto y sus pasiones llegaron a arruinar a su familia (Plb. VIII. 9. 1-3). ${ }^{8}$

\footnotetext{
${ }_{5}$ Plb XII. 26b. 4-5. Es interesante además que introduce esta referencia en un contexto de agón historiográfico con Timeo. Por otra parte, el encomio de Tersites figura más adelante entre los ejercicios de Libanio (Progymn, 8.4). 6 Plb X.21. 5-8. Theon. Prog. 110. Sobre el encomio a Filopemen de Polibio ver Pédech (1951, pp. 82-103).

7 Plb. VIII. 8. 4-7: “otros, por sus tendencias monárquicas, o bien, al contrario, por el miedo que les infunden los reyes, nos han presentado los crímenes y los sacrilegios perpetrados por Filipo en Mesenia no como un error, sino todo al revés, como algo digno de elogio, o como un castigo justo. Y no solo en lo referente a los mesenios es posible ver que los historiadores han hecho esto, sino también al tratar otras acciones de Filipo; su obra no merece tanto el nombre de historia como el de encomio".

8 Para las citas se utiliza la edición de Büttner-Wobst (1995) y las traducciones de Balasch Recort (1981).
} 
Como se advierte, el problema para Polibio es la falta de coherencia que resulta del hecho de alabar a Filipo en el comienzo del texto pero luego, en el resto de la obra, censurar su comportamiento. Es decir, para el de Megalópolis si un historiador utiliza un elogio o un vituperio lo debe hacer atendiendo a los argumentos para elaborarlos y a la coherencia interna de la obra. Recurrir a uno u otro en demasía es correr el riesgo de quitarle al relato capacidad explicativa. Por eso, Polibio señala la necesidad de ser sensato a la hora de tildar al padre de Alejandro y sus hetairoi como "afeminados", "cobardes" o "imprudentes". Porque al momento de dar lugar a sus alabanzas, esto es, como convirtieron a Macedonia en un imperio, el relato ya no resultará creíble. ${ }^{9}$

Ahora bien, la habilidad de Teopompo para componer un encomio está fuera de discusión. El que le dedicó a Filipo y Alejandro es conocido y usado en los manuales de retórica. ${ }^{10}$ Asimismo, es notorio que Polibio escribiera un encomio a Filopemen con anterioridad a su obra historiográfica. Esta peculiaridad, el haber sido primero escritores de encomios antes que historiadores, es un rasgo que Teopompo y Polibio comparten y que la mayor de las veces se pasa por alto. No obstante, en el libro X cuando Polibio introduce la figura de Filopemen en su narración histórica señala estar escribiendo historia, no un elogio. ${ }^{11}$ Luego, el de Megalópolis da cuenta de las diferencias entre ambos tipos de discurso:

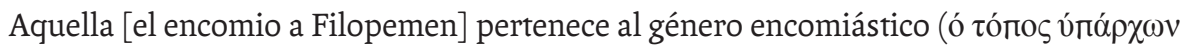
$\dot{\varepsilon} \gamma \kappa \omega \mu \iota \alpha \sigma \tau$ $\left.\sigma_{\delta}\right)$, y exigió un tratamiento resumido e hiperbólico de las gestas; el tra-

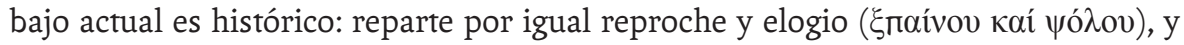
va en busca de un método correcto, que demuestre cómo uno y otro son justificados (Plb. X.21. 8).

Esa repartición igualitaria entre censura y alabanza es lo que está ausente, a juicio de Polibio, en las Filíicicas de Teopompo. ${ }^{12}$ No es que Polibio desconozca la utilidad del encomio para componer un discurso histórico; de hecho, todo el excerptum X. 21-24 está cargado de lo que en otro lugar (Olivera, 2017) ha denominado lógica encomiástica, y Evangelos Alexiou (2018) como un тó de cuál ha de ser el método correcto al que los historiadores recurran a la hora de introducir el encomio o el vituperio en sus producciones. Ese método exige dos cosas: por un lado, que los elogios y las censuras se usen con prudencia y, por otro, que puedan demostrarse.

Si, como observa también Alexiou (2018, p. 243), "la alabanza es una característica y un privilegio del encomio" y la censura lo es del vituperio, es comprensible que el relato historiográfico deba prescindir de usar uno y otro en exceso. De lo contrario, la verdadera naturaleza del discurso histórico se diluye. Un pasaje donde Polibio da cuenta del objetivo didáctico que persigue su obra puede servir para ilustrar lo que está en juego:

Es indiscutible que por este estudio nuestros contemporáneos verán si se debe rehuir la dominación romana o, por el contrario, si se debe buscar, ynuestros descendientes comprenderán si el poder romano es digno de elogio y de emulación, o si merece

\footnotetext{
9 Plb. VIII.10. 5-6. Sobre la opinión personal de Polibio respecto de la figura de Filipo II, cf. Walbank (1967, pp.85) 10 Theon. Prog. 68 y, sobre todo, 110, donde se lo utiliza como ejemplo de la práctica de conjeturar el futuro a partir del pasado.

11 Plb. X. 21-24.

12 De hecho, en su tratamiento de la figura de Filipo V, Polibio dirá: “Por eso ya al principio de esta mi obra noté una diversidad: establecí que era preciso, a veces, alabar, y, otras, condenar a unas mismas personas, ya que con frecuencia el peligro o el empeoramiento de las situaciones modifican las voluntades de los hombres, otras veces, en cambio, la varía el mejoramientos de aquellas" (Plb. XVI. 28.5).
} 


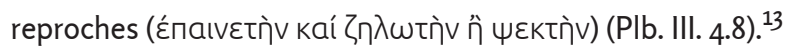

Sin embargo, no se debe sobrevalorar el grado de apego de parte de Polibio a sus propias convenciones. Bearzot (2005) está en lo cierto cuando advierte que el megalopolitano reproduce alguno de los errores que le recrimina a Teopompo. El excerptum $\mathrm{X}$. 21-24 es un ejemplo de ello. Allí Filopemen es alabado por su educación, ascendencia, buen juicio, austeridad, vocación anti-tiránica y liderazgo militar, es decir, los elogios abundan y el vituperio simplemente está ausente. ${ }^{14}$

¿Polibio contradiciendo su propio método? Puede ser. Aunque más bien la cuestión deba analizarse desde la perspectiva propuesta por Gibson (2004, p. 125) observando a qué intereses responde la inserción de un material encomiástico preelaborado en un determinado momento de la narración histórica. En ese sentido, antes (Olivera, 2017) he demostrado cómo el relato encomiástico sobre Filopemen en el libro X no puede escindirse de lo que previamente Polibio narra sobre Escipión en Hispania. Es decir, el material encomiástico no está inserto allí de casualidad, sino que busca dotar de inteligibilidad una idea muy clara en Polibio sobre el êthos del general romano, semejante al êthos de Filopemen, y, por tanto, un êthos griego.

En esa tesitura, la pregunta que parece estar detrás de la invectiva lanzada por Polibio contra Teopompo tiene que ver con cómo debe el historiador proceder con el material previamente elaborado y que, en ocasiones, fue siguiendo reglas estilísticas diferentes a las de la Historia propiamente dicha. Como Gibson (2004) ha hecho notar, todos los historiadores posclásicos aprendieron a componer en prosa trabajando con ejercicios retóricos y luego utilizaron los mismos para construir sus historias. Por tanto, es factible que la crítica polibiana pueda entenderse como una crítica a la experticia de Teopompo para hacer uso del material encomiástico en su obra historiográfica. Esa falta de experticia, según Polibio, explica el grado de incoherencias y contradicciones en que cae el historiador de Quíos.

Tal vez sea por eso que Polibio atribuye el comportamiento de Teopompo a la voluntad de escindir su obra historiográfica del encomio. En otras palabras, el megalopolitano intuye que, al injuriar a Filipo, Teopompo buscaba ser más digno de confianza como historiador, al tiempo que potenciaba su imagen como escritor de encomio al convertir en merecedor de elogio lo que es digno de censura (Walbank, 1967). ${ }^{15} \mathrm{El}$ problema es que Teopompo no prescinde del material encomiástico, su presencia es visible en el prólogo, y de ahí la incoherencia. En contraste, Polibio mantiene un hilo conductor entre lo expresado en el encomio a Filopemen y su narración histórica en X. 21-24. Por tanto, el de Megalópolis impugna el método escogido por Teopompo para trabajar con el encomio a Filipo y Alejandro en sus Filípicas.

13 Sobre el carácter didáctico de las Historias ver Moreno Leoni (2017).

14 Es claro que la crítica a Filopemen está ausente solo en este excerptum X. 21-24, pues si tenemos en cuenta los errores que comete Filopemen en la obra de Livio (con origen claramente polibiano), como cuando se embarca en una nave podrida para enfrentar a Nabis de Esparta en Gytheon y sufre una terrible derrota, o cuando se va con pocas tropas a tratar de retomar Mesene y cae prisionero. Da la idea de que es valiente, buen general y soldado, honesto, etc., pero demasiado impulsivo en la toma de decisiones. Esta es una idea que muy presente en el Filopemen de Plutarco, que trabajó sobre una base estrictamente polibiana. Obviamente Polibio es parcial pero no se priva de criticar a Filopemen. Algo de ello se trasluce en el debate del libro XXIV entre Aristeno y Filopemen (que es noble en su perspectiva, pero Aristeno es "saphós", seguro en su planteo), lo que da la idea de que Polibio no cree del todo que Filopemen sea un político muy hábil para tratar con Roma.

${ }_{15}$ PIb. VIII. 11. 1-2. "Se propuso escribir sobre un rey muy afín a la virtud... iY no hay crimen ni vileza que no le impute! $\mathrm{O}$ bien, al principio, en el mismo prefacio de su historia, Teopompo parece inevitablemente adulador y falso, o bien, en los hechos concretos, irreflexivo y pueril. En efecto, da la impresión de haber supuesto que una injuria infundada y forzada le haría más digno de confianza y convertiría en más merecedores de crédito sus elogios dirigidos a Filipo II”. 


\section{Sobre la digresión}

En esa línea de análisis se inscribe la siguiente crítica que Polibio realiza contra Teopompo en el libro XXXVIII, a propósito de las digresiones. La simpatía del historiador de Quíos por estos excursus destinados a romper el orden lineal del relato es bastante conocida. Se ha querido ver en ello un retorno al modelo de historiografía representado por Heródoto en oposición al modelo de Tucídides (Momigliano, 1984). En consecuencia, los comentaristas modernos señalan que Teopompo le atribuye a la digresión una función "composicional" (Campos Daroca y López Cruces, 1990). La opinión de Polibio, por el contrario, es otra. La cita es bastante larga, pero vale la pena trascribirla por completo:

Por eso, los más sabios de los historiadores antiguos me parece que introducían en

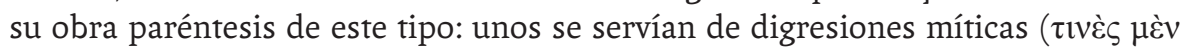

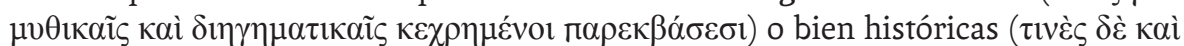

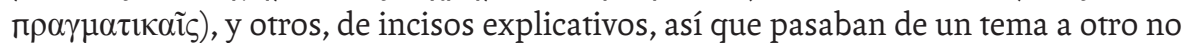
solo en los dominios de Grecia, sino también en los exteriores a ella. Quiero decir que, por ejemplo, cuando trataban los asuntos de Tesalia y los éxitos de Alejandro de Feras, intercalaban en medio los proyectos lacedemonios en cuanto al Peloponeso; luego, los hechos de los tebanos, luego, los de Macedonia o de Iliria, para derivar hablando de la campaña de Ifícrates contra Egipto o de los crímenes cometidos por Clearco en el Ponto Euxino. Se puede ver que todos los autores en cuestión han utilizado una disposición así, pero de manera desordenada, mientras que nosotros hemos introducido un orden. Ellos, en efecto, al recordar la manera como Bardilis, el rey de los ilirios, o bien Cersobleptes, el monarca tracio, adquirieron sus imperios, no añadieron la continuación ni, luego de una digresión, ofrecieron los hechos subsiguientes, sino que, como si compusieran un poema, retornaron a las posiciones iniciales. Nosotros, en cambio, tras tomar separadamente los lugares más importantes del universo y los hechos acaecidos en ellos, hemos procurado una disposición consecuente, adoptando siempre un método único para organizar el plan; hemos narrado paralelamente los hechos contemporáneos delimitándolos dentro de cada año, dejando obviamente al buen juicio de los estudiosos introducirse en el discurso seguido de los temas o en las intercalaciones propuestas; así, nada de lo citado ni quedará inconcluso ni será insuficiente para el auditorio (Plb. XXXVIII, 6. 1-7, la cursiva es nuestra).

Bearzot (2005) afirma que detrás de la acusación polibiana a Teopompo por usar muchas digresiones hay una incapacidad por comprender que esta es la forma que el de Quíos encuentra para lidiar con esa historia de los griegos, que Polibio mismo le reprocha haber abandonado en favor de una historia de Filipo. ${ }^{16}$ Sin embargo, una vez más hay que advertir que la invectiva no pasa por el uso o no de la digresión, menos por su volumen, sino por el método que debe emplear un historiador para insertar una digresión en su obra. Por más "infondata" que resulte hoy la crítica, lo cierto es que el megalopolitano tenía fundamentos concretos. ${ }^{17}$ Los mismos tenían que ver con su formación retórica y los modos que consideraba oportunos para hacer uso de los ejercicios retóricos.

16 Plb. VIII. 11. 3-5. Aquí también encontramos a Polibio realizando una crítica de algo que luego él reproduce; como señala Khellaf (2018) Polibio le da a Roma una centralidad equivalente a la de Filipo en la obra de Teopompo. Sin embargo, contra Khellaf, hay que señalar que Polibio critica el cambio de nombre de la obra, una Heleniká (en la línea de las Historias de Grecia) por una Filippiká. Polibio pretende estar más allá de eso, haciendo una historia universal tramada con el fenómeno imperial romano.

17 Se debe a Felix Jacoby el mayor esfuerzo por restituir la imagen de Teopompo en este aspecto. Al respecto cf. Walbank (1979, p. 692) y Bearzot (2005, p. 61). 


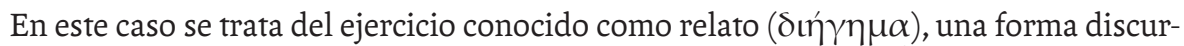
siva básica que puede servir de matriz para narraciones mayores. ${ }^{18}$ Según el retor Teón un relato puede versar sobre hechos ocurridos (reales) o aceptados como ocurridos (ficcionales). ${ }^{19} \mathrm{El}$ relato es la base tanto para la elaboración del discurso histórico como de la novela. Las virtudes que debe tener (tanto el relato como la narración que no son lo mismo) son tres: verosimilitud, concisión y claridad. Según Teón la claridad depende de dos factores: de los propios hechos y de la forma o estilo en que esos hechos sean expuestos. ${ }^{20}$ Como ejemplo de estrategias que afectan a la claridad menciona la división hecha por Tucídides de sus Historias en veranos e inviernos. Recuerda la importancia de no confundir las fechas, el orden de los hechos y no repetirse. Pero también hace una observación sobre el uso de las digresiones y cómo las mismas pueden conspirar contra la claridad de una obra. En ese contexto afirma, respecto de Teopompo, lo siguiente:

Hemos de evitar igualmente el introducir en medio de una narración $(\mu \varepsilon \tau \alpha \xi \dot{v} \delta ı$ $\gamma \eta ́ \sigma \varepsilon \omega \varsigma$ ) digresiones extensas ( necesario rehusar absolutamente toda digresión, como Filisto, ya que hace que descanse la atención de los oyentes, sino la que es tan extensa que despista la atención de los que escuchan, de modo que se necesita hacer mención de nuevo de lo dicho con anterioridad, como Teopompo en las Filípicas, pues a lo largo de una digresión encontramos dos o incluso tres y hasta más historias enteras, en las que no solo no aparece el nombre de Filipo, sino de ningún macedonio siquiera. ${ }^{21}$

Esta mención de las Filípicas como ejemplo negativo del uso de la digresión es significativa. Aunque, ciertamente, Walbank (1979) ya había reparado en esta cita en sus comentarios a la obra de Polibio, no da cuenta de sus implicancias. Porque, en efecto, Teopompo abusa de las digresiones, como en el libro VIII donde escribe un excurso tan largo que con el tiempo tendría vida independiente bajo el nombre de Tó $\theta \alpha v$ -

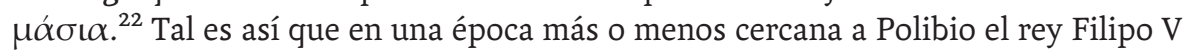
de Macedonia rehizo la obra de Teopompo, posiblemente con fines propagandísticos, suprimiendo las "numerosísimas digresiones que el historiador había introducido en su obra" (Lens, 1987, p. 49). Es decir, ni Polibio ni Teón exageran cuando señalan el "desorden" o la "falta de claridad" en que cae Teopompo con sus digresiones extensas. Dichas observaciones son el resultado de juicios previos sobre las formas correctas de componer en prosa. A esos juicios los modernos llamamos teoría progymnasmática.

Desde esta perspectiva, aquí se propone correr el foco de atención en lo que refiere a los motivos que llevan a Polibio a lanzar una invectiva contra Teopompo. El énfasis no está tanto en lo que se escribe, sino en cómo se escribe. El problema, entonces, es el modo en que el lógos resulta más efectivo para convencer respecto del conocimiento específico que el discurso historiográfico quiere transmitir. La falta de coherencia o de claridad atenta contra la mencionada efectividad del discurso. De ahí que la discusión no se concentre en la veracidad de los hechos o su interpretación, sino en la habilidad para exponerlos con claridad, concisión y verosimilitud.

Ahora bien, se puede conjeturar que el tiempo que separa la obra de Teopompo, siglo IV a. C., de la de Polibio en el siglo II a. C. dio lugar a muchos avances en materia

\footnotetext{
18 Sin embargo, los términos empleados por Polibio para digresiones narrativas consisten en formas compuestas de , como $\pi$ ("un ir aparte de"- III. 2. 7, XII. 28. 10, XXXVIII. 6.1) y $\mu$ ("pasar de un sujeto a otro "-XXXVIII. 5. 2, XXXVIII. 6.1). Cf. Khellaf (2018, p. 172).

19 Theon. Prog. 78.

20 Theon. Prog. 80.

21 Theon. Prog. 81, traducción de Reche Martínez (1991).

22 Sobre ese excurso, Campos Daroca y López Cruces (1990, pp. 75-82).
} 
de escritura de la historia y de formación retórica de los historiadores. ${ }^{23} \mathrm{El}$ grado de convencionalismo o formalización alcanzado por la educación retórica debió ser mayor en los siglos posteriores a Teopompo. Sin embargo, en muchos aspectos este continuaba siendo una referencia, en ocasiones positiva, como en el caso de la fábula o el encomio, y en otras, como vimos, negativa. La crítica de Polibio puede bien inscribirse dentro de una serie de avances en materia de formación retórica de parte de los historiadores griegos. En otras palabras, el nivel de reflexión y comprensión de las ventajas y riesgos otorgados por la retórica a la composición del discurso histórico era diferente.

Por tanto, no es casual que en un artículo reciente sobre el uso de la digresión en Polibio Kyle Khellaf (2018) haya propuesto la tesis de que fue el propio megalopolitano el que sentó las bases para reconocer la digresión como parte de la tradición historiográfica grecorromana. Los antecedentes de Éforo, Teopompo y Timeo estaban, pero es Polibio el primero que vio razones para definir cuál era el uso apropiado de la digresión como artilugio de la narrativa historiográfica. Su ejemplo fue luego imitado por los historiadores latinos y griegos, ya que ningún otro historiador de la antigüedad fue tan lejos como Polibio en hacer de la digresión una característica definitoria de la historiografía (Khellaf, 2018, p. 176).

Sin embargo, Polibio es capaz de realizar esto a partir de su formación retórica previa, la cual le daba herramientas para poder juzgar el modo en que Teopompo usaba las digresiones como un obstáculo para alcanzar la claridad expositiva. Por eso propone un "método único" que asegure el orden sin ceder en información para que nada resulte "inconcluso" o "insuficiente". Es decir, Polibio crítica, sí, pero también propone metodológicamente cómo proceder cuando se trabaja con materiales preelaborados. En el horizonte de esas propuestas metodológicas están los mismos objetivos que persiguen los manuales de retórica: evidencia, claridad, concisión, verosimilitud. Esto es así porque como observa Craig Gibson (2004, p. 126) para los historiadores de la antigüedad "La retórica formó cada aspecto del proceso de composición, desde la selección inicial del tema hasta el borrador final".

\section{Conclusión}

El propósito de este trabajo ha sido dar cuenta de dos aspectos de la escritura de la historia en Polibio que están superpuestos. Por un lado, su formación retórica, por otro, cómo la misma incide en sus juicios sobre otros historiadores. En el proceso se ha podido corroborar que el de Megalópolis incorporó en la confección de su Historia modelos de exposición y razonamiento de los hechos construidos a partir de una educación fuertemente retórica, lo que le permite proponer una forma de tratar la historia. Asimismo, los modos en que esos modelos debían organizarse en una producción discursiva mucho mayor, como es una obra historiográfica, le preocupaban y, en consecuencia, reflexionó sobre ellos. Así pues, la obra de Teopompo le permite a Polibio exponer, en forma de crítica, sus propias ideas respecto del correcto proceder que se debe tener con los ejercicios retóricos desarrollados con anterioridad.

Si censura el proceder de Teopompo no es porque lo considere un adulador, mentiroso o que improvisa, sino porque esa es la imagen que el de Quíos da de sí mismo

23 Es en el siglo IV a. C. cuando se inicia un proceso de sistematización a partir de las diferentes escuelas de retórica, la diferencia formulada por Platón entre filosofía y retórica o la delimitación intentada por Aristóteles de la retórica como téchne. También en esta época la retórica deja de ser una práctica netamente política y deviene en objeto de estudio de sí misma y en una marca de distinción cultural. 
a partir de un proceder que revela falta de experticia en el cómo se escribe la historia. Polibio aprovecha esto para presentarse, en tanto pepaideuménos, como una autoridad competente en materia de formación retórica y escritura de la historia. En otras palabras, para construir su legitimidad como historiador. Esto no quiere decir que Polibio no apelara a otros criterios igual de relevantes a la hora de fundamentar su autoridad. En efecto, el valor de la formación retórica está, en él, mediado por su autorepresentación como político y militar. ${ }^{24}$

Sin embargo, aquí interesa señalar que en los pasajes analizados Polibio no pretende impugnar la información vertida por Teopompo. Por el contrario, en el centro de su invectiva se encuentra una retorización del discurso historiográfico que se debe, en parte, a que el uso de los ejercicios retóricos está asociado a determinadas virtudes

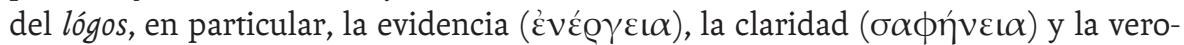

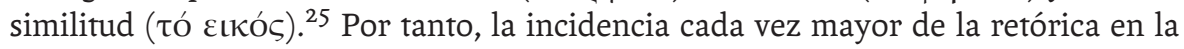
composición historiográfica resulta de un uso consciente de los ejercicios en función de generar persuasión o crear una determinada verosimilitud. Como señaló en su momento George Kennedy $(1963$, p. 7) “dondequiera que la persuasión sea el final, la retórica está presente".

En síntesis, la crítica de Polibio a Teopompo no puede escindirse de su dimensión retórica, pero no como oposición a la historia, sino como núcleo "composicional" del discurso histórico. En otras palabras, se discute la autoridad del historiador, constituida no desde un saber propiamente histórico, sino desde su formación retórica.

${ }_{24}$ Plb. XII. 25g. 1-2: "El que carece de experiencia bélica no puede describir bien lo que ocurre en la guerra, ni puede tratar de política el que no ha intervenido en sus avatares y en sus cambios”. Sobre la autorepresentación de Polibio como político y militar, ver Moreno Leoni (2017).

25 Sobre la enargeia, Zangara (2007, pp. 55-89). 


\section{Dibliografía}

» Alexiou, E. (2018). Tó $\pi \circ \varsigma \dot{\varepsilon} \gamma \kappa \omega \mu \iota \sigma \tau \imath \kappa o ́ \varsigma$ (Polybius 10.21.8): The Encomium of Philopoemen and its Isocratic Background. En N. Miltsios y M. Tamiolaki (Eds.), Polybius and His Legacy (241-255). Berlín: Walter de Gruyter.

》Balasch Recort, M. (Trad.). (1981). Polibio, Historias. Madrid: Gredos.

» Bearzot, C. (2005). Polibio e Teopompo: osservazioni di metodo e giudizio morale. En The Shadow of Polybius. Intertextuality as a Research Tool in Greek Historiography. Proceedings of the International Colloquium, Leuven, 21-22 September 2001 (55-71). Lovaina: Peeters.

» Büttner-Wobst, Th. (Ed.). (1995 [1889]). Polybii Historiae. Stuttgart: Teubner.

"Campos Daroca, J. y López Cruces, J. L. (1990). Teopompo y el saber revelado. Florentia lliberritana. Revista de Estudio de Antigüedad Clásica, 1, 75-82.

»Connor, W. R. (1967). History without Heroes: Theopompus Treatment of Philip of Macedon. GRBS, 8, 133-154.

" Gibson, C. (2004). Learning Greek History in the Ancient Classroom: The Evidence of the Treatises on Progymnasmata. CPh, 99 (2), 103-129.

"Kennedy, G. (1963). The Art of Persuasion in Greece. Princeton: Princeton University Press.

》 Khellaf, K. (2018). Incomplete and Disconnected: Polybius, Digression, and its Historiographical Afterlife. En N. Miltsios, y M. Tamiolaki (Eds.), Polybius and His Legacy (167-201). Berlín: Walter de Gruyter.

»Lens, J. (1987). Las Filípicas de Teopompo y la tradición de la caracterización psicológica en la literatura griega. Ítaca : quaderns catalans de cultura clàssica, 3, 47-70.

" Momigliano, A. (1984). Teopompo. En A. Momigliano (Ed.), La historiografía griega (168194). Barcelona: Crítica.

» Moreno Leoni, A. (2017). Entre Roma y el Mundo Griego. Memoria, autorepresentación y didáctica del poder en las Historias de Polibio. Córdoba: Editorial Brujas.

"Olivera, D. (2017). A Filopemen: historia y retórica en Polibio. Anales de Filología Clásica, $30(1), 33-42$.

"Parmeggiani, G. (2011). Eforo di Cuma. Studi di storiografia greca. Bologna: Pàtron Editore.

"Parmeggiani, G. (2018). Polybius and the Legacy of Fourth-Century Historiography. En N. Miltsios y M. Tamiolaki (Eds.), Polybius and His Legacy (277-297). Berlín: Walter de Gruyter.

"Pédech, P. (1951). Polybe et l'Éloge de Philopoemen. Revue des Études Grecques, 64, 82-103.

»Pordomingo, F. (2007). Ejercicios preliminares de la composición retórica y literaria en papiro: el encomio. En J. A. Fernández Delgado, F. Pordomingo y A. Stramaglia (Eds.), Escuela y literatura en Grecia Antigua. Actas del simposio internacional Universidad de Salamanca 17-19 noviembre de 2004 (405-453). Nápoles: La Buona Stampa-Ercolano.

»Reche Martínez, M. D. (Trad.). (1991). Teón-Hermógenes-Aftonio, Ejercicios de retórica. Madrid: Gredos.

» Thornton, J. (2013). Oratory in Polybius Histories. En C. Kremmydas y K. Tempest (Eds.), Hellenistic Oratory. Continuity and Change (20-42). Oxford: Oxford University Press. 